\title{
A EDUCAÇÃO ESCOLAR VERSUS FORMAÇÃO PROFISSIONAL E TECNOLÓGICA: LIMITES E CONTRADIÇÕES
}

\author{
Elisangela Aparecida Bulla Ikeshoji, Adriana Aparecida de Lima Terçariol, Adriano Rodrigues Ruiz \\ Universidade do Oeste Paulista - Unoeste, Mestrado em Educação, Presidente Prudente, SP. E-mail: \\ elisangela.bulla@gmail.com
}

\section{RESUMO}

A educação profissional e tecnológica no Brasil tem suas nuances seladas a partir da Lei de Diretrizes e Bases da Educação Nacional de 1996, em função da necessidade e exigências das empresas por profissionais cada vez mais qualificados. Portanto, o objetivo deste estudo é analisar como a educação profissional e tecnológica se constrói historicamente vinculada à educação escolar, na perspectiva de que a escola tem entre suas funções ser: fonte de soluções para problemas relacionados ao trabalho mercantil. O percurso metodológico escolhido é fruto de reflexão que desabrocha a partir de experiências vividas no cotidiano escolar e oriundo de estudos, debates e literatura existentes sobre o tema em questão. Realizou-se o levantamento de publicações científicas, produzidas nos últimos 15 anos, entre 2001 a 2015 na base de dados Scielo. A educação profissional e tecnológica é resultado de um processo histórico repleto de contradições e dualidades.

Palavras-chave: Educação Profissional e Tecnológica, Mercado de Trabalho, Políticas Públicas, Mercantilização da Educação.

\section{SCHOOL EDUCATION VERSUS VOCATIONAL TRAINING AND TECHONOLOGY: LIMITS AND CONTRADICTIONS}

\begin{abstract}
The vocational and technological education in Brazil has its nuances sealed from the Guidelines and Bases for National Education Law 1996, depending on the need and requirements of enterprises by increasingly skilled professionals. Therefore, the aim of this study is to analyze how the professional and technological education is built historically linked to school education, on the view that the school has among its functions to be: source of solutions to problems related to commercial work. The chosen methodological approach is reflection of fruit that blossoms from experiences in everyday school life and come from studies, debates and existing literature on the subject in question. It conducted a survey of scientific publications, produced over the last 15 years, from 2001 to 2015 in Scielo database. The vocational and technological education is the result of a historical process full of contradictions and dualities.
\end{abstract}

Keywords: Professional and Technological Education, Labour Market, Public Policy, Education Commodification 


\section{INTRODUÇÃO}

A educação profissional e tecnológica no Brasil tem suas nuances seladas a partir da Lei de Diretrizes e Bases da Educação Nacional de 1996, em função da necessidade e exigências das empresas por profissionais cada vez mais qualificados (FAVRETTO; MORETTO, 2013; TAKASHASHI, 2010). Diante deste cenário, a educação parece representar para o capital o negócio mais rentável e fecundo, entende-se assim, sob esta perspectiva que fica evidente a mercantilização da educação (FRIGOTTO, 2007).

A educação no seu sentido mais amplo cumpre na escola duas funções complexas, sendo uma de socialização formal dos conhecimentos conquistados pela humanidade, essenciais para humanização do homem, e outra, a formação do cidadão para sua intervenção na comunidade humana. E na escola, assim como em qualquer instituição social pode-se encontrar espaços de relativa autonomia para desiquilibrar a reprodução conservadora do status quo (FARTES; SANTOS, 2011; GÓMEZ, 1998).

Contudo, cabe a escola o grande desafio educativo, atenuar os efeitos da desigualdade, assim como preparar o indivíduo para se defender frente ao cenário social (GÓMEZ, 1998). Portanto, o objetivo deste estudo é analisar como a educação profissional e tecnológica se constrói historicamente vinculada à educação escolar, na perspectiva de que a escola tem, entre seus compromissos, ser fonte de soluções para problemas relacionados ao trabalho mercantil.

\section{METODOLOGIA}

Este trabalho é fruto de reflexão que desabrocha a partir de experiências vividas no cotidiano escolar e oriundo de estudos, debates e literatura existentes sobre o tema em questão. Realizou-se o levantamento de publicações científicas, na base de dados Scielo (Scientific Electronic Library - http://www.scielo.org/php/index.php.), produzidas nos últimos 15 anos, entre 2001 a 2015, que discutem a educação profissional e tecnológica no Brasil. Utilizou-se do descritor "Educação Profissional e Tecnológica", localizado vinte e sete artigos dos quais dez foram selecionados, conforme tabela 1 , tendo por base que no resumo houve um viés com o objetivo desta pesquisa.

A escolha por essa base de dados se justifica por ela estar disponível aos usuários, com acesso aberto, online, possibilita o acesso a artigos completos publicados em periódicos que abrangem várias áreas do conhecimento, além de ter diversas revistas indexadas. A partir desta etapa, esses artigos foram lidos na íntegra para que fosse possível identificar as ideias principais e nortear a essência dos próximos tópicos a serem apresentados, no decorrer deste trabalho. 
TABELA 1 - Artigos selecionados: Descritor "Educação Profissional e Tecnológica".

\begin{tabular}{|l|l|c|}
\hline No & $\begin{array}{l}\text { Autor (es) / Artigo } \\
01\end{array}$ & $\begin{array}{c}\text { Revista / Estrato } \\
\text { Qualis / Ano } \\
\text { Publicação }\end{array}$ \\
\hline 02 & $\begin{array}{l}\text { CATANI, A. M.; OLIVEIRA, J. F. de; DOURADO, L. F. Política } \\
\text { educacional, mudanças no mundo do trabalho e reforma curricular } \\
\text { na cultura docente da educação profissional e tecnológica. }\end{array}$ & $\begin{array}{c}\text { Educaça \& } \\
\text { Sociedade / A2 / 2001 }\end{array}$ \\
\hline 03 & $\begin{array}{l}\text { FAVRETTO, J.; MORETTO, C. F. Os cursos superiores de tecnologia } \\
\text { no contexto de expansão da educação superior no Brasil: a } \\
\text { retomada da ênfase na educação profissional. }\end{array}$ & $\begin{array}{l}\text { Sociedade / A2 / 2013 } \\
\text { / A1 / 2011 }\end{array}$ \\
\hline 04 & $\begin{array}{l}\text { FERRETTI, C. J. Mudanças em sistemas estaduais de ensino em face } \\
\text { das reformas no Ensino Médio e no Ensino Técnico. }\end{array}$ & $\begin{array}{c}\text { Educação \& } \\
\text { Sociedade /A2 / 2000 }\end{array}$ \\
\hline 05 & $\begin{array}{l}\text { FOGUEL, F. H. dos S.; NORMANHA FILHO, M. A. Um fator de } \\
\text { desenvolvimento de clusters no Brasil: a educação profissional. }\end{array}$ & $\begin{array}{c}\text { Cadernos EBAPE.BR } \\
\text { /B1 / 2007 }\end{array}$ \\
\hline 06 & $\begin{array}{l}\text { FRIGOTTO, G. A relação da educação profissional e tecnológica com } \\
\text { a universalização da educação básica. }\end{array}$ & $\begin{array}{c}\text { Educação \& } \\
\text { Sociedade / A2 / 2007 }\end{array}$ \\
\hline 07 & $\begin{array}{l}\text { RIBEIRO, M. Políticas públicas em trabalho, educação e tecnologia: } \\
\text { uma história em movimento. }\end{array}$ & $\begin{array}{l}\text { Trabalho, Educação e } \\
\text { Saúde / B1 / 2006 }\end{array}$ \\
\hline 08 & $\begin{array}{l}\text { SILVEIRA, R. M. C. F.; BAZZO, W. Ciência, tecnologia e suas relações } \\
\text { sociais: a percepção de geradores de tecnologia e suas implicações } \\
\text { na educação tecnológica. }\end{array}$ & $\begin{array}{c}\text { Ciência Educação } \\
\text { (Bauru) / A1 / 2009 }\end{array}$ \\
\hline 09 & $\begin{array}{l}\text { TAKAHASHI, A. R. W. Cursos superiores de tecnologia em gestão: } \\
\text { reflexões e implicações da expansão de uma (nova) modalidade de } \\
\text { ensino superior em administração no Brasil. }\end{array}$ & $\begin{array}{l}\text { Revista de } \\
\text { Administração Pública } \\
\text { / A2 / 2010 }\end{array}$ \\
\hline 10 & $\begin{array}{l}\text { TAKAHASHI, A. R. W.; AMORIM, W. A. C. de. Reformulação e } \\
\text { dificuldades da retomada da educação profissional. }\end{array}$ & $\begin{array}{l}\text { Ensaio: Avaliação e } \\
\text { Políticas Públicas em } \\
\text { Educação / A1 / 2008 }\end{array}$ \\
\hline
\end{tabular}

\section{As Escolas de Aprendizes Artífices e os Liceus}

Em 23 de setembro de 1909, por meio do Decreto no 7.566, o governo federal cria e instala em 19 capitais dos Estados da Republica Escolas de Aprendizes Artífices, para o ensino profissional primário e gratuito (BRASIL, 1909). Exceto em Porto Alegre e no Distrito Federal, pois eram mantidas pelos seus governos e tinha a mesma função das então criadas escolas (CUNHA, 2000b).

O movimento de expansão das escolas profissionais, no território brasileiro, esta vinculado ao processo de urbanização e industrialização, devido à necessidade de força de trabalho qualificada. A única opção de qualificação daqueles que eram excluídos do ensino secundário, eram as escolas de aprendizes artífices. Portanto, de caráter assistencialista e político-ideológico, pois, considera-se perigoso a instrução nas classes inferiores da sociedade (VILLELA, 2011; CUNHA, 2000a; CUNHA, 2000b). 
As escolas de aprendizes artífices, instituída pela Lei $\mathrm{n}$ ㅇ 378, de 13 de janeiro de 1937, denominada de Liceu. O ensino profissional primário passa a se configurar da seguinte maneira: ensino primário com conteúdo exclusivamente geral para depois o ensino profissional de primeiro grau e todos os ramos. O dever do Estado com o ensino primário obrigatório e gratuito parece decorrer da necessidade de qualificação de trabalhadores para as indústrias. Esta dualidade na educação será percebida com mais ou menos intensidade durante o trajeto da educação profissional. Pois, "uma educação básica de baixa qualidade redunda numa pífia educação profissional." (FRIGOTO, 2007, p. 1129).

Com a crise mundial de 1930, houve a necessidade de focalizar não somente no setor primário, mas também secundário, em que as indústrias demandam por trabalhadores mais qualificados. Portanto, o ensino oferecido pelos liceus atenderá em partes as necessidades futura de formação para o trabalho, pois carece de uma educação geral como a oferecida no ensino secundário (CUNHA, 2005).

\section{O Ensino Industrial e as Escolas Técnicas Federais}

Em 30 de janeiro de 1942, o Decreto-Lei no 4.073, introduziu a lei orgânica do ensino industrial o que implicou em decisão governamental de realizar profundas alterações na organização do ensino técnico. A partir dessa reforma ocorreu todo o deslocamento do ensino técnico industrial para o grau médio e o ensino primário organizado com conteúdo exclusivamente geral (CUNHA, 2005). Infelizmente, "a essência da lei, que é sua adaptabilidade às demandas do capital para a formação de um trabalhador flexível e a baixo custo." (RIBEIRO, 2006, p. 276).

Todavia, a lógica de organização da educação para o ensino profissional para atender a necessidade do mercado precisa ser bem articulada, conforme explicito na lei $n$ ㅇ 4.073/1942 sobre as providências para o desenvolvimento do estado industrial. E o Decreto-Lei no 4.127 de 25 de fevereiro de 1942, estabelece a organização para a rede federal de ensino industrial e institui as escolas técnicas e industriais, local exclusivo para o ensino industrial.

A Lei no 4.759, de 20 de agosto de 1965, denomina de Escola Técnica Federal as escolas técnicas e industriais federais, tornando clara sua vinculação direta à União. A Lei de Diretrizes e Bases da Educação Nacional (LDB) no 4.024 de 1961 permitia a equivalência dos cursos técnicos ao ensino secundário (ensino médio), sendo que os alunos egressos dos cursos técnicos podiam ingressar em quaisquer dos cursos superiores, não sendo mais obrigatório o curso superior ter que ser o mesmo do curso técnico escolhido. 
Esta articulação tem um aspecto favorável de adequação às necessidades industriais, que buscavam trabalhadores qualificados - correspondente ao 2ㅇ ciclo e outros sem qualificação especial que a aprendizagem profissional pudesse suprir. "Em sentido contrário ao do trabalho como princípio educativo de uma formação omnilateral." (RIBEIRO, 2006, p. 273).

\section{Centro Federal de Educação e Tecnologia e Instituto Federal de Educação, Ciência e Tecnologia}

A Lei no 6.545 de 30 de junho de 1978, dispõe sobre a transformação das escolas técnicas federais em Centros Federais de Educação Tecnológica (CEFET), que tem por finalidade a formação dos profissionais na área tecnológica, em grau superior de graduação, especialização, mestrado e doutorado. Assim também, licenciaturas para formação de professores especializados em disciplinas específicas do ensino técnico e tecnológico. E cursos técnicos, em nível de segundo grau com vistas a formar técnicos, instrutores e auxiliares de nível médio (BRASIL, 1978).

A Lei de Diretrizes e Bases da Educação Nacional (LDB) no 9.394/96 "traz uma concepção marcadamente profissionalizante do ensino médio, em oposição à concepção nitidamente profissional da educação técnica." (CUNHA, 2005, p. 253). Este modelo de educação não oferece base e conhecimento para o aluno ingressar na educação superior.

Para Takashi e Amorim (2008), assim como Ferretti (2000), a preocupação com a educação profissional se volta para uma formação atrelada à exigência do mercado de trabalho, inclusive menciona que o Brasil parece querer despertar para a relevância da relação trabalho educação, mas só desperta, não prossegue. Esta "necessidade" da sociedade contemporânea pode ser compreendida quando se observa na pesquisa realizada por Silveira e Bazzo (2009) com 29 participantes (empreendedores e gestores de empresas). Os resultados mostraram que a grande maioria dos empreendedores e gestores possui uma visão ainda incipiente sobre ciência, tecnologia e suas relações sociais.

A Lei no 11.892 de 29 de dezembro de 2008, institui o Instituto Federal de Educação, Ciência e Tecnologia, tem como característica fundamental atender à demanda das empresas por mão de obra qualificada. Para isto, $50 \%$ de suas vagas são, essencialmente, disponibilizadas para os cursos técnicos, $20 \%$ licenciaturas e $30 \%$ conforme necessidade da demanda social da região. (BRASIL, 2008).

Segundo pesquisa desenvolvida por Foguel e Normanha Filho (2007), o modelo de arranjo produtivo local (APL), é altamente recomendável para o fortalecimento de segmentos da economia. Considera-se como pressuposto que a competitividade e ampliação do ciclo de vida destes aglomerados dependem de educação profissional contextualizada. No entanto, quando a 
educação profissional e tecnológica é pensada apenas para atender o mercado de trabalho, o que ocorre é uma mercantilização da educação segundo Catani, Oliveira e Dourado (2001).

\section{CONSIDERAÇÕES FINAIS}

A educação profissional e tecnológica é resultado de um processo histórico repleto de contradições e dualidades. Portanto, a educação não poder dar conta de resolver problemas que não são da sua alçada, pois analisar a qualificação como elemento isolado de ausência de crescimento econômico é insuficiente.

Todavia, é difícil para escola acompanhar a dinâmica imposta pela exigência do trabalho, até porque é muito pertinente indagar se a exigência por parte das empresas em profissionais qualificados não tem como pano de fundo o recrutar e selecionar profissionais no mercado de recursos humanos devido à existência de mão-de-obra abundante (ARAÚJO; BORGES, 2000).

Portanto, a educação carece de ser compreendida, na sua complexidade e função. Assim como, na relação com as esferas econômicas, políticas e sociais. A função de exclusiva utilidade da escola na sua relação com a formação para o trabalho mercantil é que preocupa.

\section{REFERÊNCIAS}

ARAUJO, M. A. D. de; BORGES, D. F. Globalização e mercado de trabalho: educação e empregabilidade. Organizações \& Sociedade, Salvador, v. 7, n. 17, p. 9-16, Abr. 2000. Disponível em: <http://www.scielo.br/scielo.php?script=sci_arttext\&pid=S1984-

92302000000100001\&lng=en\&nrm=iso>. Acesso em: 05 ago. 2015.

BRASIL. Decreto no 7566, de 23 de setembro de 1909. Crêa nas capitães dos Estados da Republica Escolas de Aprendizes Artífices, para o ensino profissional primário e gratuito. Diário Oficial da União, Rio de Janeiro, RJ, 26 de set. de 1909. Disponível em: <http://www2.camara.leg.br/legin/fed/decret/1900-1909/decreto-7566-23-setembro-1909525411-publicacaooriginal-1-pe.html>. Acesso em: 19 mai. 2015.

BRASIL. Lei no 378, de 13 de janeiro de 1937. Dá nova, organização ao Ministério da Educação e Saúde Pública. Diário Oficial da União, Rio de Janeiro, RJ, 15 jan. 1937. Disponível em: <https://www.planalto.gov.br/ccivil_03/leis/1930-1949/I0378.htm>. Acesso em: 19 mai. 2015.

BRASIL. Decreto-Lei no 4073, de 30 de janeiro de 1942. Lei orgânica do ensino industrial. Diário Oficial da União, Rio de Janeiro, RJ, 09 fev. 1942. Disponível em: <http://www2.camara.leg.br/legin/fed/declei/1940-1949/decreto-lei-4073-30-janeiro-1942414503-publicacaooriginal-1-pe.html>. Acesso em: 20 jun. 2015.

BRASIL. Decreto-Lei no 4127, de 25 de fevereiro de 1942. Estabelece as bases de organização da rede federal de estabelecimentos de ensino industrial. Diário Oficial da União, Rio de Janeiro, RJ, 27 fev. 1942. Disponível em: <http://www2.camara.leg.br/legin/fed/declei/1940-1949/decretolei-4127-25-fevereiro-1942-414123-publicacaooriginal-1-pe.html>. Acesso em: 20 jun. 2015. 
BRASIL. Lei no 4024, de 20 de dezembro de 1961. Fixa as Diretrizes e Bases da Educação Nacional. Diário Oficial da União, Brasília, DF, 27 dez. 1961. Disponível em: <http://www2.camara.leg.br/legin/fed/lei/1960-1969/lei-4024-20-dezembro-1961-353722publicacaooriginal-1-pl.html>. Acesso em: 30 jun. 2015.

BRASIL. Lei no 4759, de 20 de agosto de 1965. Dispõe sobre a denominação e qualificação das Universidades e Escolas Técnicas Federais. Diário Oficial da União, Brasília, DF, 24 ago. 1965. Disponível em: <http://www2.camara.leg.br/legin/fed/lei/1960-1969/lei-4759-20-agosto-1965368906-publicacaooriginal-1-pl.html>. Acesso em: 30 jun. 2015.

BRASIL. Lei no 6545, de 30 de junho de 1978. Dispõe sobre a transformação das Escolas Técnicas Federais de Minas Gerais, do Paraná e Celso Suckow da Fonseca em Centros Federais de Educação Tecnológica e dá outras providências. Diário Oficial da União, Brasília, DF, 04 jul. 1978. Disponível em:<http://www.planalto.gov.br/CCivil_03/LEIS/L6545.htm>. Acesso em: 20 jun. 2015.

BRASIL. Lei no 9394, de 20 de dezembro de 1996. Estabelece as diretrizes e base da educação nacional. Diário Oficial da União, Brasília, DF, 23 dez. 1996. Disponível em:

<http://www.planalto.gov.br/CCIVIL_03/leis/L9394.htm>. Acesso em: 20 jun. 2015.

BRASIL. Lei no 11892, de 29 de dezembro de 2008. Institui a Rede Federal de Educação Profissional, Científica e Tecnológica, cria os Institutos Federais de Educação, Ciência e Tecnologia, e dá outras providências. Diário Oficial da União, Brasília, DF, 30 dez. 2008. Disponível em: <http://www.planalto.gov.br/ccivil_03/_ato2007-2010/2008/lei/l11892.htm>. Acesso em: 19 mai. 2015.

CATANI, A. M.; OLIVEIRA, J. F. de; DOURADO, L. F. Política educacional, mudanças no mundo do trabalho e reforma curricular dos cursos de graduação no Brasil. Educação \&

Sociedade, Campinas, v. 22, n. 75, p. 67-83, Ago. 2001. Disponível em:

$<$ http://www.scielo.br/scielo.php?script=sci_arttext\&pid=S0101-

73302001000200006\&lng=en\&nrm=iso>. Acesso em: 18 jul. 2015.

CUNHA, L. A. $O$ ensino de ofícios artesanais e manufatureiros no Brasil escravocrata. São Paulo: Editora UNESP, Brasília, DF: Flacso, 2000a.

CUNHA, L. A. O ensino de ofícios nos primórdios da industrialização. São Paulo: Editora UNESP, Brasília, DF: Flacso, 2000b.

CUNHA, L. A. O ensino profissional na erradicação do industrialismo. São Paulo: Editora UNESP, Brasília, DF: Flacso, 2005.

FARTES, V.; SANTOS, A. P. Q. O. Saberes, identidades, autonomia na cultura docente da educação profissional e tecnológica. Cadernos de Pesquisa, São Paulo, v. 41, n. 143, p. 376-401, Ago. 2011. Disponível em: <http://www.scielo.br/scielo.php?script=sci_arttext\&pid=S010015742011000200004\&lng=en\&nrm=iso>. Acesso em: 18 jul. 2015.

FAVRETTO, J.; MORETTO, C. F. Os cursos superiores de tecnologia no contexto de expansão da educação superior no Brasil: a retomada da ênfase na educação profissional. Educação \& Sociedade, Campinas, v. 34, n. 123, p. 407-424, Jun. 2013. Disponível em: 
<http://www.scielo.br/scielo.php?script=sci_arttext\&pid=S010173302013000200005\&lng=en\&nrm=iso>. Acesso em: 18 jul. 2015.

FERRETTI, C. J. Mudanças em sistemas estaduais de ensino em face das reformas no Ensino Médio e no Ensino Técnico. Educação \& Sociedade, Campinas, v. 21, n. 70, p. 80-99, Abr. 2000.

Disponível em: <http://www.scielo.br/scielo.php?script=sci_arttext\&pid=S0101$73302000000100006 \&$ Ing=en\&nrm=iso>. Acesso em: 18 jul. 2015.

FOGUEL, F. H. dos S.; NORMANHA FILHO, M. A. Um fator de desenvolvimento de clusters no Brasil: a educação profissional. Cadernos EBAPE.BR, Rio de Janeiro, v. 5, n. 1, p. 01-16, Mar. 2007. Disponível em: <http://www.scielo.br/scielo.php?script=sci_arttext\&pid=S167939512007000100010\&lng=en\&nrm=iso>. Acesso em: 18 jul. 2015.

FRIGOTTO, G. A relação da educação profissional e tecnológica com a universalização da educação básica. Educação \& Sociedade, Campinas, v. 28, n. 100, p. 1129-1152, Out. 2007. Disponível em: $<$ http://www.scielo.br/scielo.php?script=sci_arttext\&pid=S010173302007000300023\&lng=en\&nrm=iso>. Acesso em: 18 jul. 2015.

GÓMEZ, A. I. P. As funções sociais da escola: da reprodução à reconstrução crítica do conhecimento e da experiência. SACRISTÁN, J. G.; GÓMEZ, A. I. P. In: Compreender e transformar o ensino. Porto Alegre: Artmed, 1998. p. 13-26.

VILLELA, A. B. O instituto profissional masculino Bento Quirino: uma visão social ideológica, maçônica, industrial e republicana. 2011. 132 f. Dissertação (Mestrado em Educação) Universidade Estadual de Campinas, Campinas - SP. Disponível em: <http://www.bibliotecadigital.unicamp.br/document/?code $=000868555 \& \mathrm{fd}=\mathrm{y}>$. Acesso em: 20 jun. 2015.

RIBEIRO, M. Políticas públicas em trabalho, educação e tecnologia: uma história em movimento. Trabalho, Educação e Saúde, Rio de Janeiro, v. 4, n. 2, p. 259-290, Set. 2006. Disponível em: <http://www.scielo.br/scielo.php?script=sci_arttext\&pid=S1981$77462006000200004 \&$ Ing=en\&nrm=iso>. Acesso em: 18 jul. 2015.

SILVEIRA, R. M. C. F.; BAZZO, W. Ciência, tecnologia e suas relações sociais: a percepção de geradores de tecnologia e suas implicações na educação tecnológica. Ciências Educação (Bauru), Bauru, v. 15, n. 3, p. 681-694, 2009. Disponível em:

<http://www.scielo.br/scielo.php?script=sci_arttext\&pid=S151673132009000300014\&lng=en\&nrm=iso>. Acesso em: 18 jul. 2015.

TAKAHASHI, A. R. W. Cursos superiores de tecnologia em gestão: reflexões e implicações da expansão de uma (nova) modalidade de ensino superior em administração no Brasil. Revista de Administração Pública, Rio de Janeiro, v. 44, n. 2, p. 385-414, Abr. 2010. Disponível em: $<$ http://www.scielo.br/scielo.php?script=sci_arttext\&pid=S0034$76122010000200009 \&$ Ing=en\&nrm=iso>. Acesso em: 18 jul. 2015.

TAKAHASHI, A. R. W.; AMORIM, W. A. C. de. Reformulação e expansão dos cursos superiores de tecnologia no Brasil: as dificuldades da retomada da educação profissional. Ensaio: Avaliação e Políticas Públicas em Educação, Rio de Janeiro, v. 16, n. 59, p. 207-228, Jun. 2008. Disponível em: 
<http://www.scielo.br/scielo.php?script=sci_arttext\&pid=S0104-

$40362008000200004 \&$ Ing=en\&nrm=iso>. Acesso em: 18 jul. 2015. 